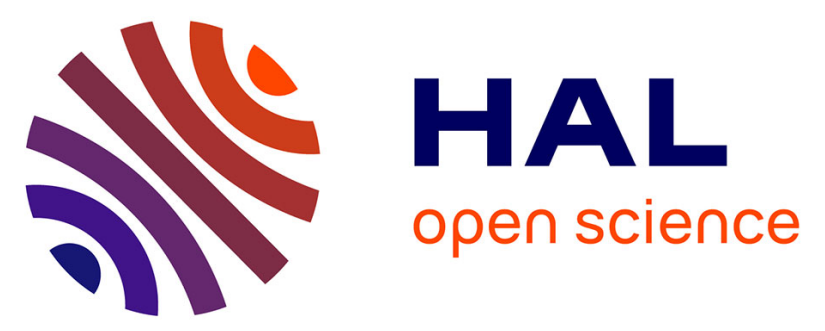

\title{
Recrystallization of Industrial Triple Super Phosphate Powder
}

Khouloud Nasri, Chaker Chtara, Chekir Hassen, Marina Fiallo, Patrick

Sharrock, Ange Nzihou, Hafed El Felki

\section{- To cite this version:}

Khouloud Nasri, Chaker Chtara, Chekir Hassen, Marina Fiallo, Patrick Sharrock, et al.. Recrystallization of Industrial Triple Super Phosphate Powder. Industrial and engineering chemistry research, 2014, 53 (37), p. 14446-14450. 10.1021/ie502033j . hal-01611982

\section{HAL Id: hal-01611982 \\ https://hal.science/hal-01611982}

Submitted on 15 Jan 2019

HAL is a multi-disciplinary open access archive for the deposit and dissemination of scientific research documents, whether they are published or not. The documents may come from teaching and research institutions in France or abroad, or from public or private research centers.
L'archive ouverte pluridisciplinaire $\mathbf{H A L}$, est destinée au dépôt et à la diffusion de documents scientifiques de niveau recherche, publiés ou non, émanant des établissements d'enseignement et de recherche français ou étrangers, des laboratoires publics ou privés. 


\title{
Recrystallization of Industrial Triple Super Phosphate Powder
}

\author{
Khouloud Nasri, ${ }^{\dagger, \nabla}$ Chaker Chtara, ${ }^{\ddagger}$ Chekir Hassen, ${ }^{\ddagger}$ Marina Fiallo, ${ }^{\dagger}$ Patrick Sharrock, ${ }^{\dagger, \S, *}$ Ange Nzihou, ${ }^{\S}$ \\ and Hafed El Feki ${ }^{\nabla}$ \\ ${ }^{\dagger}$ SIMAD Laboratory, Institut Universitaire de Technologie, Université de Toulouse, Castres, France \\ †unisian Chemical Group Research Directorate ZI, BP72-6000-Gabes, Tunisia \\ ${ }^{\S}$ Centre RAPSODEE, Université de Toulouse, Mines Albi, CNRS , Albi, France \\ ${ }^{\nabla}$ Laboratory of Sciences of Materials and Environment, Sfax Faculty of Sciences, Soukra Road km 4, BP n 802-3038 Sfax, Tunisia
}

\begin{abstract}
Raw calcium phosphate obtained by adding phosphoric acid to phosphate ore yields industrial triple super phosphate (TSP), consisting of calcium phosphate that contains many impurities. TSP was dissolved in a minimum amount of water, filtered to remove insoluble compounds and evaporated to dryness. This produced monocalcium phosphate monohydrate of high purity and solubility. The starting materials and final recrystallized products were analyzed by several methods (X-ray diffraction (XRD), infrared (IR), nuclear magnetic resonance (NMR), thermogravimetry-differential scanning calorimetry (TGDSC), scanning electron microscopy (SEM)) confirming that the purified product is monocalcium phosphate monohydrate that can be used as a soluble fertilizer free of contaminants.
\end{abstract}

\section{INTRODUCTION}

The major source of phosphorus fertilizer is phosphate rock, originating from fossilized animal bone deposits. Such raw ores are mined to manufacture phosphoric acid, and some ground ores are used as inexpensive fertilizer. ${ }^{1}$ However, phosphate rock delivers phosphorus at a very slow rate, because of its insolubility in water, and modern agricultural practices favor the use of rapidly bioavailable phosphorus, such as that found in monoammonium phosphate or diammonium phosphate. ${ }^{2,3} \mathrm{~A}$ convenient and economical process for making a fertilizer containing soluble phosphate is to react phosphoric acid with the raw ore to form triple super phosphate (TSP). In this beneficiation process, the total $\mathrm{P}$ that becomes available is the sum of the phosphate added as acid plus the phosphate released from the ore by the acid attack. The reaction of interest may be written as in reaction 1 :

$$
\begin{aligned}
& 14 \mathrm{H}_{3} \mathrm{PO}_{4}+\mathrm{Ca}_{10}\left(\mathrm{PO}_{4}\right)_{6}(\mathrm{OH})_{2} \\
& \left.\quad \rightarrow 10\left[\mathrm{Ca}\left(\mathrm{H}_{2} \mathrm{PO}_{4}\right)_{2} \cdot \mathrm{H}_{2} \mathrm{O}\right)\right]+2 \mathrm{H}_{2} \mathrm{O}
\end{aligned}
$$

This idealized reaction implies that phosphoric acid reacts preferentially with the hydroxyapatite (HA) (or fluoroapatite) in the ore and not with the main impurities (iron oxides, alumina, and silicates).

To improve the contents in soluble phosphorus, i.e., the purity of the TSP, it is possible to dissolve the reaction products in water and remove the insoluble fraction by filtration, thus recovering the soluble monocalcium phosphate monohydrate (MCPM) in solution. However, it is known from the thermodynamics of the $\mathrm{Ca}(\mathrm{OH})_{2}-\mathrm{H}_{3} \mathrm{PO}_{4}-\mathrm{H}_{2} \mathrm{O}$ system that HA is the most stable product. ${ }^{4}$ In other words, any solid with $\mathrm{Ca} / \mathrm{P}<1.67$ will hydrolyze in solution to release phosphoric acid and form $\mathrm{HA}$ or other reaction products with higher $\mathrm{Ca} / \mathrm{P}$ ratio than the starting solid. It is expected, for instance, that MCPM will hydrolyze according to reaction 2:

$$
\left.\left[\mathrm{Ca}\left(\mathrm{H}_{2} \mathrm{PO}_{4}\right)_{2} \cdot \mathrm{H}_{2} \mathrm{O}\right)\right] \rightarrow \mathrm{CaHPO}_{4}+\mathrm{H}_{3} \mathrm{PO}_{4}
$$

On the other hand, the reactions do not go to completion, unless a mechanism is present to remove the acid. Equilibrium will be reached at a $\mathrm{pH}$ value where the composition of the solution reaches the intersection of the solubility isotherms, when the solution is saturated, with respect to all mineral phases.

It is the aim of this report to identify the yield in reaction products and the nature of the calcium phosphates formed by reacting phosphoric ore with phosphoric acid and extracting the available phosphorus in aqueous solution.

\section{EXPERIMENTAL SECTION}

The starting product used was Tunisian TSP (triple super phosphate) obtained industrially by reacting ore from the Gafsa deposits with raw $33 \% \mathrm{H}_{3} \mathrm{PO}_{4}$. The dry product was a freeflowing powder. Elemental compositions were obtained by Xray fluorescence (XRF) with a PANalytical Epsilon instrument from Philips. Scanning electron microscopy (SEM) images were obtained from an ESEM XL30 from Philips. Infrared (IR) spectra were recorded with a Nicolet Impact 410 spectrometer in the DRIFT mode with no sample preparation. Thermal analysis was investigated with a Q600 from TA Instruments. Powder X-ray diffraction (XRD) patterns were obtained with a Bruker D2 Phaser diffractomer. ${ }^{31} \mathrm{P}$ and ${ }^{1} \mathrm{H}$ NMR were obtained with a Bruker Avance 300 spectrometer. Synthetic MCPM was made by adding a stoichiometric amount of calcium oxide to a solution of phosphoric acid, stirring, and allowed the mixture to stand overnight at $40{ }^{\circ} \mathrm{C}$ in an oven, then letting the solids dry in air. Conductivity measurements 
were performed using a Metrhom Herisau 712 conductometer. Calcium in solid phosphates was analyzed by precipitation as the oxalate followed by manganimetric titration. $\mathrm{P}_{2} \mathrm{O}_{5}$ was analyzed by a gravimetric method envolving molybdate precipitation. These methods are described in more detail in the standards used in industry. ${ }^{5}$

\section{RESULTS AND DISCUSSION}

The raw TSP contains a large proportion of phosphate with a $\mathrm{Ca} / \mathrm{P}$ ratio of 0.57 , and $\mathrm{P}_{2} \mathrm{O}_{5}$ contents of $48.6 \%$. The major cation is calcium and the minor elements are iron (2\%), silicon $(2 \%)$, and magnesium $(1 \%)$, followed by trace elements $(\mathrm{Sr}$, $0.5 \%, \mathrm{Cr}, 0.13 \%)$.

The amount of water used to dissolve the raw TSP was determined according to industry standards meant to optimize water use, i.e., minimize water consumption. The dissolution of phosphogypsum, followed by the same conductivity measurements method, was presented recently. ${ }^{6}$ In the present work, as illustrated in Figure 1, the conductivity of the solution reaches a

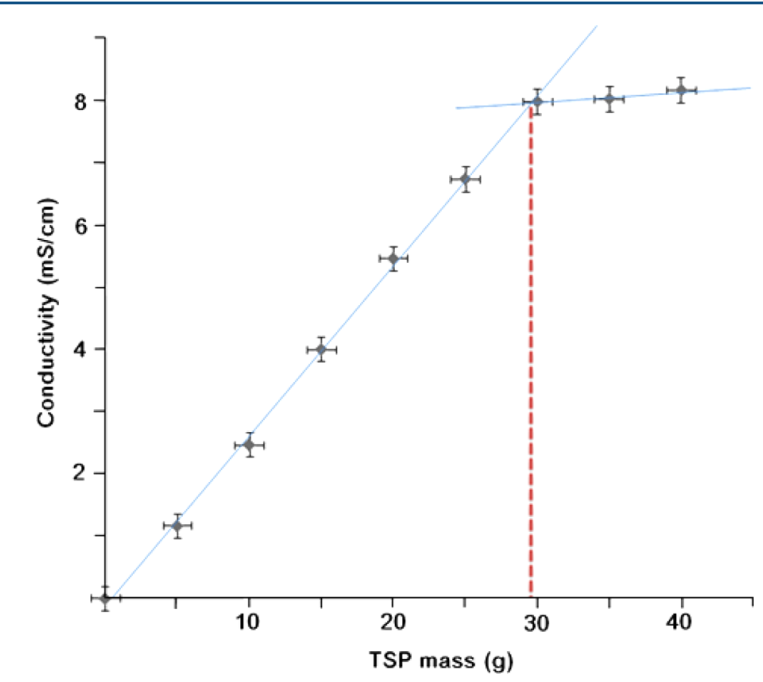

Figure 1. Titration curve showing the conductivity of $100 \mathrm{~mL}$ of solution, as a function of the mass of triple super phosphate (TSP) introduced.

maximum value at a ratio of $29.65 \mathrm{~g}$ of TSP for $100 \mathrm{~mL}$ of $\mathrm{H}_{2} \mathrm{O}$ at $25{ }^{\circ} \mathrm{C}$. From this data, a solubility product of $K_{\mathrm{sp}}=4.07 \times$ $10^{-1}$ was derived for calcium dihydrogen phosphate. This solidto-liquid ratio was used for making the subsequent samples. The liquid phase was evaporated at $50{ }^{\circ} \mathrm{C}$ under a reduced pressure of 200 mbar to recover dry solids (recrystallized TSP). Table 1 summarizes the elemental composition of the raw TSP, and of the nondissolved solids. The composition of the solids resulting from evaporation of the liquid phase (recrystallized TSP) is also listed for completeness.
The recrystallized TSP contains much less impurities $(\mathrm{Fe}$, $<0.05 \%$; $\mathrm{Mg}, 0.6 \%$; $\mathrm{Sr}, 0.5 \%$; $\mathrm{Cr},<0.04 \%)$, whereas the undissolved solids contain more ( $\mathrm{Fe}, 3 \%$; $\mathrm{Si}, 3 \%$; $\mathrm{Al}, 1.5 \%$; $\mathrm{Mg},>1 \%, \mathrm{Cr},>0.2 \%$; $\mathrm{Sr},>0.4 \%$; $\mathrm{Zn}, 0.1 \%)$. At $25^{\circ} \mathrm{C}, 69 \%$ of the products are in the liquid phase and $31 \%$ are in the solid phase.

The IR spectra illustrating the main phosphate vibrations near $1000 \mathrm{~cm}^{-1}$ are shown in Figure 2. The spectra also present

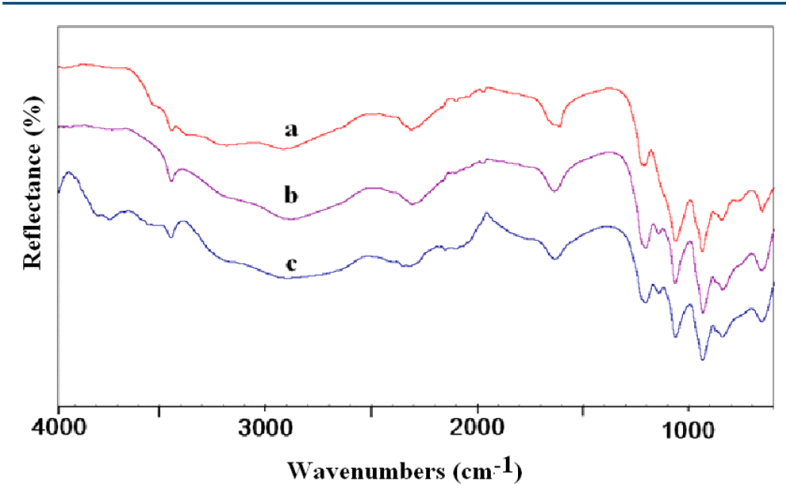

Figure 2. Infrared (IR) spectra of (a) raw TSP, (b) recrystallized TSP, and (c) synthetic TSP.

water molecule scissoring modes at $1600 \mathrm{~cm}^{-1}$, and $\mathrm{OH}$ stretching vibrations from $3300 \mathrm{~cm}^{-1}$ to $3700 \mathrm{~cm}^{-1}$. Fully deprotonated orthophosphate IR absorption occurs at 1005 $\mathrm{cm}^{-1}$, but when partially protonated, acid phosphate groups present separate $\mathrm{PO}$ vibrations and multiple peaks. The spectra obtained for raw or recrystallized TSP have five main peaks, at $665,847,946,1072$, and $1215 \mathrm{~cm}^{-1}$. These results are similar to those reported by Desai et al. ${ }^{7}$ and Fernández et al., 8 in a previous report on calcium phosphate cements, or by Boonchom, ${ }^{10}$ who performed a study of the rapid precipitation of MCPM in aqueous acetone media. The spectra agree with that obtained for the synthetic MCPM. The water absorption bands are located at 1650 and $3458 \mathrm{~cm}^{-1}$ for free water and $2900 \mathrm{~cm}^{-1}$ for bound water, in agreement with Boonchom. ${ }^{10}$

The ${ }^{1} \mathrm{H}$ NMR confirms the presence of water protons and acid phosphate protons and is presented in Figure 3, together with the ${ }^{31} \mathrm{P}$ NMR spectra, illustrating multiple phosphate species. Proton NMR of the raw TSP solid has an ill-resolved peak between 0 and $20 \mathrm{ppm}$ with a maximum at $11.84 \mathrm{ppm}$, whereas the recrystallized product has well-resolved water protons at $7.43 \mathrm{ppm}$ and acid phosphate protons at $11.71 \mathrm{ppm}$. The synthetic MCPM also reveals water protons at $7.49 \mathrm{ppm}$ and acid phosphate protons occurring as an unresolved multiplet at $12.005 \mathrm{ppm}$. These values correspond to that calculated by Pourpoint et al. ${ }^{11}$ with acid protons ranging from $9.9 \mathrm{ppm}$ to $12.2 \mathrm{ppm}$, while water protons are calculated to be observed at $5.1 \mathrm{pp}$ and $6.4 \mathrm{ppm}$. Pourpoint et al. ${ }^{11}$ reported the experimental ${ }^{31} \mathrm{P}$ NMR spectrum to have two peaks for MCPM related to the two different phosphorus environments with

Table 1. Chemical Analysis of Major Elements (\%), Minor Elements (\%) and Trace Elements (ppm) in Raw and Recrystallized TSP

\begin{tabular}{|c|c|c|c|c|c|c|c|c|c|c|c|}
\hline \multirow[b]{2}{*}{ component } & \multicolumn{3}{|c|}{ Major Elements (\%) } & \multicolumn{5}{|c|}{ Minor Elements (\%) } & \multicolumn{3}{|c|}{ Trace Elements (ppm) } \\
\hline & $\mathrm{CaO}$ & $\mathrm{P}_{2} \mathrm{O}_{5}$ & $\mathrm{H}_{2} \mathrm{O}$ & $\mathrm{MgO}$ & $\mathrm{Fe}_{2} \mathrm{O}_{3}$ & $\mathrm{Al}_{2} \mathrm{O}_{3}$ & $\mathrm{SiO}_{4}$ & $\mathrm{SO}_{3}$ & $\mathrm{Cr}$ & $\mathrm{Zn}$ & $\mathrm{Cd}$ \\
\hline raw TSP & 21.9 & 48.5 & 9 & 1.6 & 2.8 & 0.8 & 2.1 & 16.5 & 191 & 216 & 26 \\
\hline recrystallized TSP & 21.7 & 57.5 & 7 & 1.0 & 0.07 & 0.01 & 1.1 & 1.7 & 51 & 91 & 7 \\
\hline
\end{tabular}




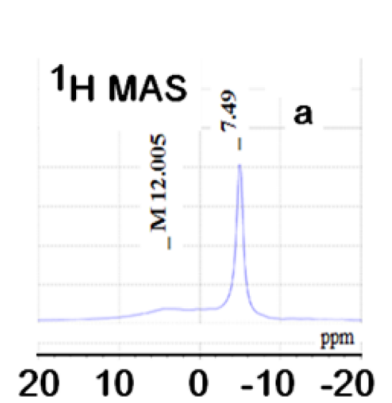

31 P MAS 五

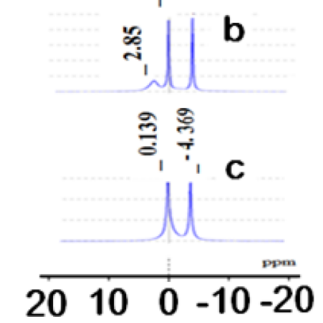

Figure 3. Nuclear magnetic resonance (NMR) spectra of (a) synthetic TSP, (b) raw TSP, and (c) recrystallized TSP (MCPM).

signals at -4.2 and $0.3 \mathrm{ppm}$. Our synthetic MCPM or recrystallized TSP samples also show peaks at -4.4 and 0.16 $\mathrm{ppm}$. The proton cross-polarized NMR also has strong peaks at -4.5 and $0.02 \mathrm{ppm}$, but the decoupled MAS spectrum reveals an additional peak centered at $2.85 \mathrm{ppm}$, related to remaining $\mathrm{HA}$ in the raw sample. Because pure HA has no protons on the phosphate groups, no enhancement of the ${ }^{31} \mathrm{P}$ resonance occurs by cross-polarization with protons, minimizing this peak compared to the acid phosphate protons in cross-polarized spectra. $^{12}$

$\mathrm{XRD}$ patterns for a selected $2 \theta$ range from $5^{\circ}$ to $25^{\circ}$ are presented in Figure 4 to illustrate the presence of main

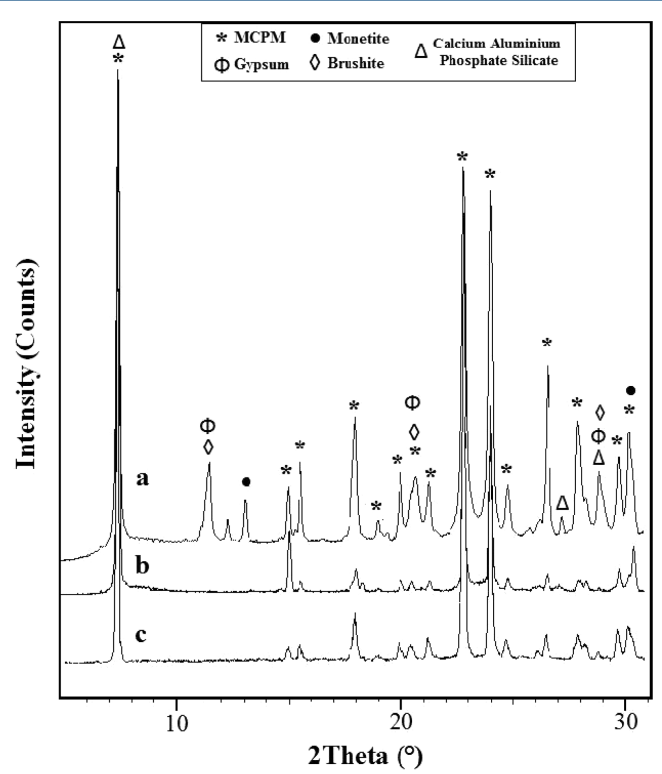

Figure 4. X-ray diffraction (XRD) patterns of (a) raw TSP, (b) recrystallized TSP, and (c) synthetic TSP.

crystalline phases. The XRD pattern of raw TSP shows a strong diffraction at $2 \theta$ value of $7.5^{\circ}$, and two other sharp lines at $23^{\circ}$ and $24.2^{\circ}$. These lines are characteristic for MCPM, as can be seen by comparison with the recrystallized product or synthetic material, and corresponding to the Joint Committee for Powder Diffraction Data Standards (JCPDS) reference (File Card No. 00-003-0284). Other substances are identified in the TSP by their XRD lines at $2 \theta$ values of $11.7^{\circ}$, and smaller signals at $21^{\circ}$, $26.5^{\circ}, 29.4^{\circ}$, and $30.3^{\circ}$ values. These reflections arise from monetite and confirm that the raw TSP contains a mixture of MCPM and other minor minerals as discussed above, whereas the recrystallized product is pure MCPM. The analysis of the solid residue left after dissolution of the TSP in water reveals a small amount of MCPM remaining undissolved, and a smaller amount of monetite, which was observed in small amounts in the raw TSP. Further water washing effectively dissolved the remaining MCPM yet left a detectable amount of monetite that could not be dissolved at neutral or basic $\mathrm{pH}$ values.

Thermal analysis results are presented as thermogravimetric analysis (TGA) and differential scanning calorimetry (DSC) curves in Figure 5 and illustrate the loss of water via

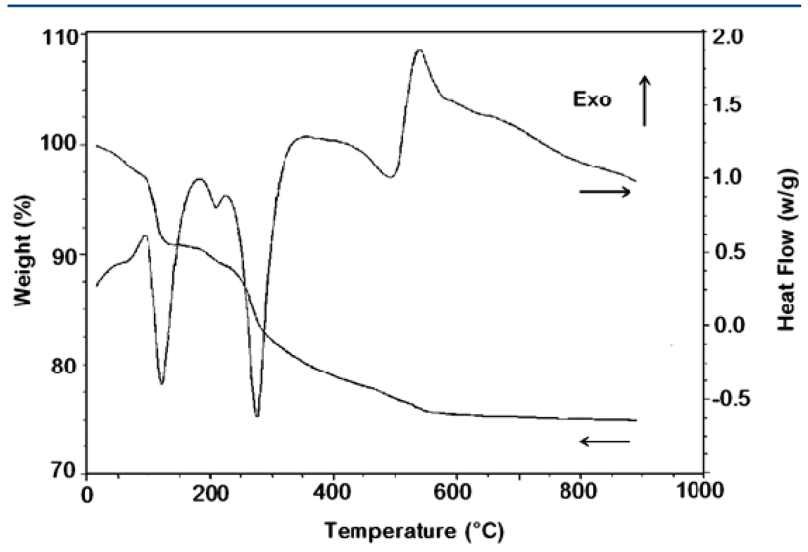

Figure 5. Thermogram of recrystallized TSP; left scale shows weight loss, right scale shows heat flow.

dehydration and via the formation of pyrophosphates. Thermal analysis shows that MCPM looses water then forms amorphous calcium pyrophosphate $\left(\mathrm{CaH}_{2} \mathrm{P}_{2} \mathrm{O}_{7}\right)$ at $220{ }^{\circ} \mathrm{C} .{ }^{13}$ We observed the multistep dehydration reactions in our TGA curves, and found the exothermic transformation of the calcium pyrophosphate $\left[\mathrm{Ca}\left(\mathrm{H}_{2} \mathrm{P}_{2} \mathrm{O}_{7}\right)_{2}\right]$ to calcium metaphosphate $\mathrm{CaP}_{2} \mathrm{O}_{6}$ at $530{ }^{\circ} \mathrm{C} .{ }^{13}$ Comparable results were reported previously by Boonchom. ${ }^{10}$ In this solid, phosphate has both bridging and terminal $\mathrm{P}-\mathrm{O}$ bonds with average bond lengths of $1.584 \AA$ and $1.487 \AA$, respectively. ${ }^{14}$

SEM observations, illustrated in Figure 6, confirm the formation of MCPM crystals as $5 \mu \mathrm{m}$ plates or larger for the synthetic product. The recrystallized crystals are slightly smaller in size but of similar appearance in shape. The special feature of the MCPM crystals is that the crystallites seem to be embedded in an amorphous phase, which analyses for a lower $\mathrm{Ca} / \mathrm{P}$ ratio than 0.5 . This agrees with the observation that commercial grades of MCPM will always contain a proportion of monetite derived from hydrolysis according to reaction 3:

$$
\mathrm{Ca}\left(\mathrm{H}_{2} \mathrm{PO}_{4}\right)_{2}+\mathrm{H}_{2} \mathrm{O} \rightarrow \mathrm{CaHPO}_{4}+\mathrm{H}_{3} \mathrm{PO}_{4}+\mathrm{H}_{2} \mathrm{O}
$$

Thus, the released phosphoric acid will remain between the MCPM crystals and form an amorphous-like phase as the water evaporates. Similar images were found by Boonchom ${ }^{10}$ and Desai et al. ${ }^{7}$

\section{CONCLUSION}

Raw TSP manufactured by reaction of phosphoric acid with phosphate ore has a relatively high $\mathrm{P}_{2} \mathrm{O}_{5}$ content of $48.6 \%$. The recrystallization of this product in water dissolves monocalcium phosphate monohydrate (MCPM), with a higher $\mathrm{P}_{2} \mathrm{O}_{5}$ content of $57.5 \%$. This represents the highest amount of soluble phosphate observed to date in solid form with calcium. In the raw ore, the amount of phosphoric acid added represents 

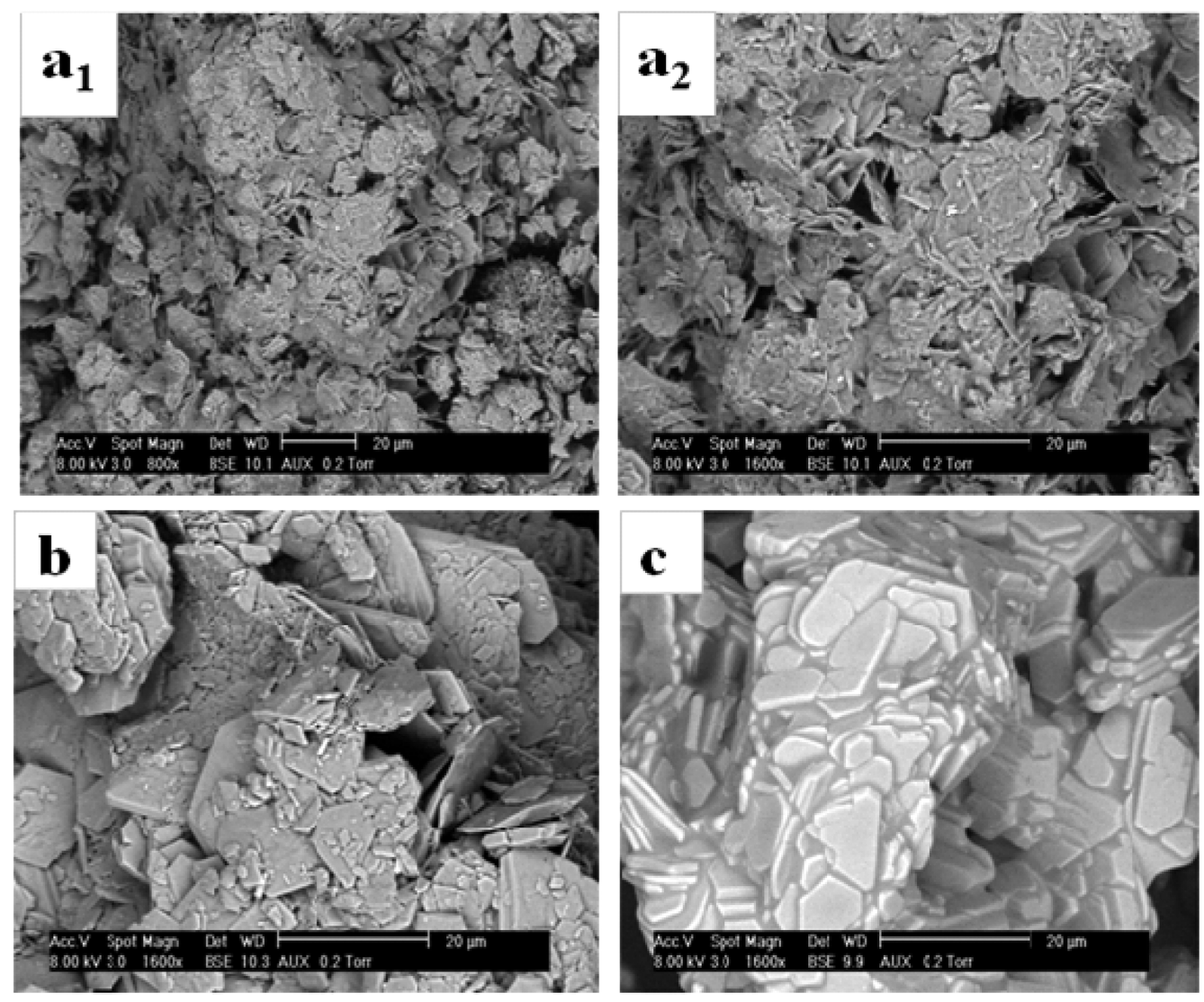

Figure 6. Scanning electron microscopy (SEM) images of $\left(a_{1}\right.$ and $\left.a_{2}\right)$ raw TSP, (b) synthetic TSP, and (c) recrystallized TSP.

$13.34 \%$ of free acid. In the raw TSP, we experimentally found $51.31 \%$ free acid, and in the purified MCPM, we found $76.98 \%$ free acid. Thus, the amount of free acid (soluble phosphate) was 5 times greater, compared to the amount introduced in the ore. The amount of available phosphate was increased by $50 \%$ in the pure MCPM compared to the TSP. The losses due to handling and the fact that, following filtration, the residue contains 52\% water, retaining some MCPM dissolved and not recovered by rinsing, amount to $6.8 \%$. Therefore, the combined process is largely justified because much more available phosphate becomes soluble in the end product than the amount introduced in the ore.

MCPM is not stable in water solution and tends to lose $\mathrm{H}_{3} \mathrm{PO}_{4}$ and transform to $\mathrm{CaHPO}_{4}$, either when diluted or by heating the aqueous solution above $50{ }^{\circ} \mathrm{C}$. Use of this recrystallized compound as fertilizer will bring the largest amount of available phosphorus with the lowest quantity of insoluble impurities. However, it is known that a fraction of soluble phosphorus reacts in soils to form insoluble compounds (for instance, calcium, iron, or aluminum phosphates) by reacting with the mineral elements in soils. Despite such transformations, ${ }^{15,16}$ the phosphates may still be mobilized later on by soil manure additions or plants during diagenesis and the production of organic acids by phytometabolism.

\section{AUTHOR INFORMATION}

\section{Corresponding Author}

*E-mail: patrick.sharrock@iut-tlse3.fr.

\section{Notes}

The authors declare the following competing financial interest(s): Drs. Chtara and Hassen work for the Tunisian fertilizer industry.

\section{REFERENCES}

(1) Bolan, N. S.; White, R. E.; Hedley, M. J. A review of the use of phosphate rocks as fertilizers for direct application in Australia and New Zealand. Aust. J. Exp. Agric. 1990, 30 (2), 291-313.

(2) Ross, W. H.; Merz, A. R.; Jacob, K. D. Preparation and properties of the ammonium phosphates. Ind. Eng. Chem. 1929, 21, 286-289.

(3) Montalvo, D.; Degryse, B.; McLaughlin, M. J. Fluid Fertilizers Improve Phosphorus Diffusion but not Lability in Andisols and Oxisols. Soil Sci. Soc. Am. J. 2014, 78 (1), 214-224.

(4) Koutsoukos, P.; Amjad, Z.; Tomson, M. B.; Nancollas, G. H. Crystallization of calcium phosphates. A constant composition study. J. Am. Chem. Soc. 1980, 102 (5), 1553-1557.

(5) Fertilizers-Determination of phosphorus content-Quinoline phosphomolybdate gravimetric method, ISO 6598:1985; International Organization for Standardization (ISO): Geneva, Switzerland, 1985.

(6) Hammas, I.; Horchani-Naifer, K.; Férid, M. Solubility study and valorization of phosphogypsum salt solution. Int. J. Miner. Process. 2013, 123, 87-93.

(7) Desai, T. R.; Bhaduri, S. B.; Taş, A. C. A self-setting monetite $\left(\mathrm{CaHPO}_{4}\right)$ cement for skeletal repair. In Advances in Bioceramics and Biocomposites II; The American Ceramic Society: Westerville, OH, 2007; pp 61-69.

(8) Fernández, E.; Gil, F. J.; Ginebra, M. P.; Driessens, F. C. M.; Planell, J. A.; Best, S. M. Calcium Phosphate Bone Cements for Clinical Applications, Part I: Solution Chemistry. J. Mater. Sci: Mater. Med. 1999, 10, 169-176. 
(9) Fernández, E.; Gil, F. J.; Ginebra, M. P.; Driessens, F. C. M.; Planell, J. A.; Best, S. M. Calcium Phosphate Bone Cements for Clinical Applications, Part II: Precipitate Formation during Setting Reactions. J. Mater. Sci: Mater. Med. 1999, 10, 177-184.

(10) Boonchom, B. Parallelogram-like microparticles of calcium dihydrogen phosphate monohydrate $\left(\mathrm{Ca}\left(\mathrm{H}_{2} \mathrm{PO}_{4}\right)_{2}, \mathrm{H}_{2} \mathrm{O}\right)$ obtained by a rapid precipitation route in aqueous and acetone media. J. Alloy Compds. 2009, 482, 199-202.

(11) Pourpoint, F.; Gervais, C.; Bonhomme-Coury, L.; Aaïs, T.; Coelho, C.; Mauri, F.; Alonso, B.; Babonneau, F.; Bonhomme, C. Calcium Phosphates and Hydroxyapatite: Solid-State NMR Experiments and First-Principles Calculations. Appl. Magn. Reson. 2007, 32, 435-457.

(12) Tsai, T. W.; Chan, J. C. Recent progress in solid state NMR of biomineralization. Ann. Rep. NMR Spectrosc. 2011, 73, 1-61.

(13) Gilmour, R. Phosphoric Acid: Purification, Uses, Technology, and Economics; CRC Press, Taylor \& Francis Group: Boca Raton, FL, 2014; Chapter 5, pp 237-244.

(14) Wetherall, K. M.; Pickup, D. M.; Newport, R. J.; Mountjoy, G. The structure of calcium metaphosphate glass obtained from X-ray and neutron diffraction and reverse Monte Carlo modelling. J. Phys.: Condens. Matter 2009, 21, 1-9.

(15) McBeath, T. M.; Lombi, E.; McLaughlin, M. J.; Bünemann, E. K. Exchangeability of orthophosphate and pyrophosphate in soil: a double isotopic labeling study. Plant Soil 2009, 314, 243-252.

(16) Gikonyo, E. W.; Zaharah, A. R.; Hanafi, M. M.; Anuar, R. A. Phosphorus Leaching in an Acid Tropical Soil "Recapitalized" with Phosphate Rock and Triple Superphosphate. Sci. World J. 2010, 10, 1498-1508. 